\title{
DNA BARCODE E SEXAGEM MOLECULAR DE TIRANÍDEOS (AVES: TYRANNIDAE) DA ÁREA DE PROTEÇÃO AMBIENTAL DO PRATIGI, BAHIA
}

\author{
$\underline{\text { Rozivane de Jesus Silva }}{ }^{1}$; Caio Graco Machado ${ }^{2}$ e Eddy José Francisco de Oliveira ${ }^{3}$ \\ 1. Bolsista PROBIC/UEFS, Graduando em Ciências Biológicas, Universidade Estadual de Feira de Santana, e-mail: \\ rozivanee@hotmail.com \\ 2. Orientador, Departamento de Ciências Biológicas, Universidade Estadual de Feira de Santana, e-mail: gracom@uol.com.br \\ 3. Co-orientador, Departamento de Ciências Biológicas, Universidade Estadual de Feira de Santana, e-mail: \\ eddyfo@gmail.com
}

PALAVRAS-CHAVE: Sexagem, DNA Barcode, aves.

\section{INTRODUÇÃO}

O Brasil apresenta uma das maiores diversidades de aves do mundo, com 1901 espécies, das quais 270 espécies endêmicas do Brasil segundo o Comitê Brasileiro de Registros Ornitológicos (CBRO, 2014). A avifauna, pela sua diversidade e ocupação de papéis ecológicos, muitos dos quais, chave nas comunidades, representa um dos elementos de maior eficácia para indicar as condições ambientais, auxiliando na identificação de processos de degradação e na criação e implantação de medidas conservacionistas (Gonzaga 1986).

No intuito de preservar um remanescente importante da Mata Atlântica do sul da Bahia, foi criada em 1998, em uma área de 85.686 ha, a Área de Proteção Ambiental do Pratigi (APA do Pratigi), que abrange cinco municípios (Ibirapitanga, Igrapiúna, Ituberá, Nilo Peçanha e Piraí do Norte). As investigações sobre a avifauna da Mata Atlântica do baixo sul da Bahia, ainda são incipientes e concentradas, sobretudo, na costa do cacau (Cordeiro 2000, Cordeiro 2003, Laps et al 2003, Silveira 2005). Esta situação é totalmente insatisfatória diante de uma região com rica biodiversidade de fauna e flora e que vem sofrendo, historicamente, grandes agressões e transformações.

Coleções ornitológicas sempre foram centros de produção e difusão do conhecimento básico sobre a diversidade e distribuição de aves no Brasil congregando dados acerca da avifauna de uma região, sua biogeografia e ecologia e estudos de anatomia, taxonomia e sistemática molecular, importantes para subsidiar políticas conservacionistas de ambientes e espécies, além da descrição de novos táxons (Vuilleumier 1998; Aleixo \& Straube 2007). A Divisão de Aves do Museu de Zoologia da Universidade Estadual de Feira de Santana (DAMZFS), lotada no Laboratório de Ornitologia/UEFS, foi criada em 2005 (Deliberação CGEN no 121 de 05/08/2005; DOU 01/09/2005) e além de conter espécimes taxidermizadas, também conta com as coleções de tecidos (amostra de material genético) e de carcaças e vísceras dos espécimes tombados, conservadas em álcool 70\%, cujo objetivo é fornecer material para investigações genéticas, propiciando importante instrumento para o apoio de pesquisa genética da avifauna do nordeste, visando o entendimento de questões evolutivas e biogeográficas das aves, assim como sua conservação.

Algumas espécies de aves não apresentam dimorfismo sexual, dificultando a distinção entre machos e fêmeas, apenas pela morfologia externa. Atualmente, uma das maneiras mais seguras e efetivas de realizar a identificação de machos e fêmeas em diversas espécies de aves é por meio da denominada "sexagem molecular", em que se analisa uma determinada porção do genoma que apresenta diferenças entre os sexos. Como as aves apresentam um sistema de determinação sexual do tipo ZZ (machos) / ZW (fêmeas), um marcador ideal para identificação de sexo nestes animais pode ser considerado um DNA único ao cromossomo sexual W, presente unicamente nas fêmeas (Miyaki et al. 1998 apud Gonçalves 2013).

Dados genéticos têm sido cada vez mais utilizados na Ornitologia para complementar dados morfológicos, ecológicos, biogeográficos, entre outros (Myiaki 2010). A necessidade 
de se estudar a rica biodiversidade da Mata Atlântica com a finalidade de conhecê-la e principalmente preservá-la são, sobretudo devido ao alto índice de endemismo que este ambiente apresenta. Nesse sentido, a sexagem molecular em aves se faz necessária em espécies que não possuem dimorfismo sexual, tornando-se valiosa ferramenta para estudos de conservação e de populações.

\section{MATERIAL E MÉTODOS OU METODOLOGIA (ou equivalente)}

\section{Exemplares amostrados}

O material biológico usado no trabalho, foram amostras de tecidos de espécimes que foram coletadas na APA do Pratigi, baixo sul da Bahia e encontram-se armazenadas na DAMZFS .

\section{Extração e amplificação do DNA}

Em laboratório fizemos a extração do DNA total, as amostras que estiveram armazenadas a $-20^{\circ} \mathrm{C}$, usamos para tal o protocolo segundo Higuchi (1989) com algumas alterações. Para amplificação das regiões do DNA mitocondrial, foram selecionados os primers P2 e P8 específicos para aves.

As reações de PCR foram realizadas em volume total de $25 \mu 1$ contendo $3 \mu 1$ de tampão Taq 10x com (NH4)2SO4; $1 \mu 1$ de dNTP mix 2,5mM; $1 \mu 1 \mathrm{MgCl} 225 \mathrm{mM} ; 1 \mu 1$ de cada primer

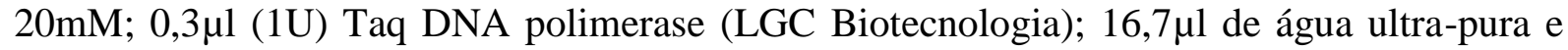
$1 \mu l$ de DNA total. A amplificação foi conduzida em termociclador (Biocycler ${ }^{\circledR}-$ MJ96G) usando o seguinte programa: um ciclo de desnaturação a $94{ }^{\circ} \mathrm{C}$ com duração de 5 minutos, seguido de 35 ciclos de: desnaturação a $94^{\circ} \mathrm{C}$ por $1 \mathrm{~min}$, anelamento por $1 \mathrm{~min}$ e 20 segundos a $42^{\circ} \mathrm{C}$ e elongação por 1 min a $72^{\circ} \mathrm{C}$ e um ciclo de extensão final a $72^{\circ} \mathrm{C}$ por 20 min.

Os fragmentos amplificados foram submetidos à eletroforese em gel de agarose a $2 \%$, corado com GelRed ${ }^{\mathrm{TM}}$ (Biotinum, Inc., EUA). Sendo utilizado na corrida de eletroforese um marcador de peso molecular de 100 pares de base (pb) Ladder (GE Healthcare $\left.{ }^{\circledR}\right)$. Os fragmentos foram visualizados em transluminador e fotografados.

Para identificação do sexo das aves, reações de amplificação (PCR - Polymerase Chain Reaction) foram realizadas conforme protocolo descrito por Miyaki et. al. (1998), utilizando os primers P2 (5'-TCTGCATCGCTAAATCCTTT-3') e P8 (5'CTCCCAAGGATGAGRAAYTG-3'), originalmente descritos por Griffths et al. (1998). Estes primers foram desenhados para amplificar uma região do gene CHD-W, ligado ao cromossomo sexual W, e o gene CHD-Z, presente no cromossomo sexual Z. Desta forma, são amplificados dois fragmentos de DNA de diferentes tamanhos nas fêmeas e apenas um fragmento em machos (Miyaki et. al. 1998).

\section{RESULTADOS E/OU DISCUSSÃO (ou Análise e discussão dos resultados)}

As ferramentas moleculares permitiram a separação entre machos e fêmeas de 13 espécies de aves da família Tyrannidae. Foram analisadas amostras de tecido de 19 exemplares, provenientes da Área de Proteção Ambiental do Pratigi. As 13 espécies de tiranídeos foram: Rhytipterna simplex, Muscipipra vetula, Myiarchus tuberculifer, Lathrotriccus euleri, Attila rufus, Megarynchus pitangua, Myiozetetes similis, Elaenia spectabilis, Elaenia sp.1, Elaenia mesoleuca, Elaenia sp.2, Phaeomyas murina, Stigmatura budytoides. Foram analisados 5 espécimes de Rhytipterna simplex e 2 espécimes de Elaenia mesoleuca, as demais cada uma tiveram 1 espécime analisado. A identificação de machos e fêmeas em diversas espécies de aves pode ser realizada através da "sexagem molecular", onde se analisa uma determinada porção do genoma que apresenta diferenças entre os sexos. Como as aves apresentam um sistema de determinação sexual do tipo ZZ (machos) / ZW (fêmeas), 
um segmento de DNA único ao cromossomo sexual W presente unicamente nas fêmeas pode ser considerado um marcador ideal para identificação do sexo nestes animais (MIYAKI et al., 1998). Um destes marcadores identificados em aves refere-se ao gene CHD (cromohelicaseDNA-ligante) - o gene CHD-Z é encontrado no cromossomo Z, ocorrendo, portanto em ambos os sexos, enquanto o gene CHD-W localiza-se no cromossomo W, presente somente nas fêmeas (GRIFFITHS et al., 1998). O conjunto de oligonucleotídeos mais comumente utilizado para identificação do sexo em aves refere-se aos primers denominados P2 e P8 (GRIFFITHS et al., 1998) que se anelam a regiões conservadas de éxons dos genes CHD-Z e CHD-W e amplificam uma região de íntron que difere em tamanho entre os dois genes, resultando na identificação de um único fragmento de DNA em machos (genótipo homozigoto) e de dois fragmentos distintos em fêmeas (genótipo heterozigoto) (GRIFFITHS et al., 1998 apud GONÇALVES, 2013 ).

Diante disto, no presente trabalho, a identificação do sexo das aves foi feita através da amplificação dos genes CHD-Z e CHD-W utilizando os primers P2 e P8 em PCR. Da amplificação dos genes foi possível visualizar um ou dois fragmentos de DNA em gel de agarose $2 \%$, em que dois fragmentos evidenciam fêmeas e um único fragmento evidencia machos (Figura1). Portanto, os resultados obtidos confirmam o proposto por GRIFFITHS et al.(1996, 1998), que o conjunto de primers P2 e P8 é o mais adequado para amplificação de segmentos de DNA de diferentes tamanhos associados aos genes CHD-Z e CHD-W, permitindo, assim, a execução da sexagem molecular com exatidão em diversas espécies de aves. Outros trabalhos, que também utilizaram a metodologia proposta por GRIFFITHS et al. (1998) para determinar o sexo de diferentes aves, apresentaram resultado eficaz.

Existem várias técnicas para a identificação do sexo em aves, porém a análise de DNA confere um alto grau de confiabilidade ao resultado. Nem sempre conseguimos identificar o gênero de uma ave apenas pelas características morfológicas e lou comportamentais observadas, às vezes até mesmo a identificação do sexo, em espécies com dimorfismo sexual, pode ser dificultada, pois algumas características são muitos sutis ou só se expressam no período de maturidade sexual. Assim sendo, dados sobre sexagem em aves se fazem fundamentais em estudos sobre manejo e conservação de espécies, além de ser importante também em estudos sobre estrutura populacional, comportamento e ecologia animal.

Os resultados alcançados no presente trabalho demonstram que foi possível implantar, junto ao Laboratório de Ornitologia e ao Laboratório de Entomologia molecular (Departamento de Ciências Biológicas - UEFS), a metodologia de sexagem molecular de aves. Apesar das análises terem sido restritas a algumas espécies, pode se conceber que os resultados positivos sirvam de base para a implantação futura de um serviço regular de sexagem molecular de aves.

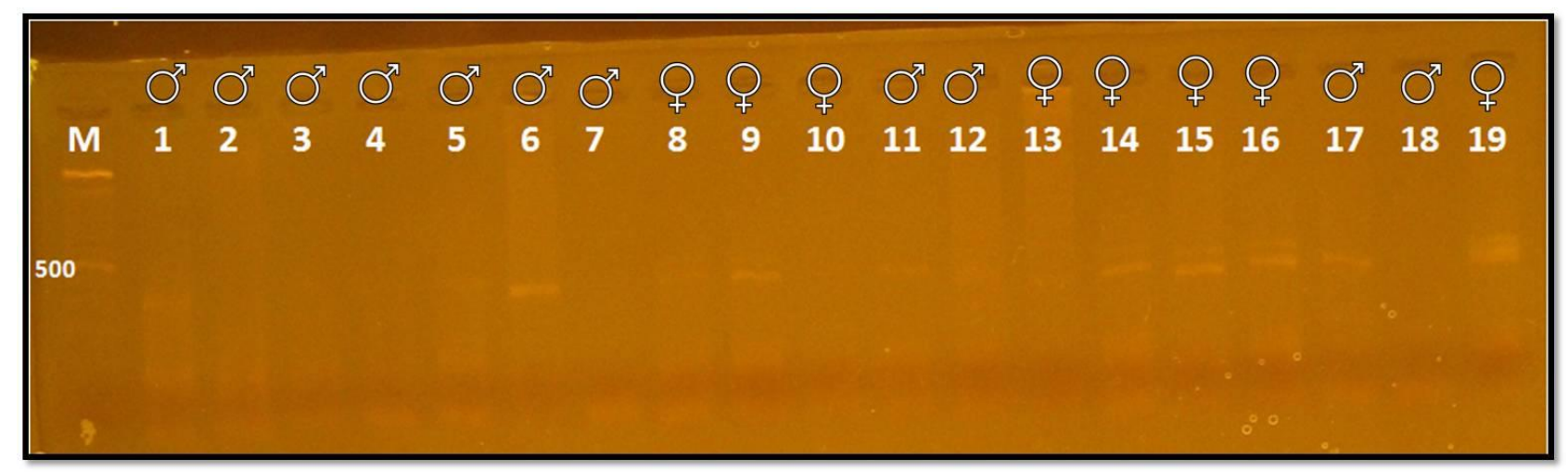

Figura1. Sexagem molecular de tiranideos com os genes CDH (Primers P2 e P8). 1 - Elaenia spectabilis; 2 - Elaenia sp.1; 3 - Elaenia mesoleuca; 4 - Elaenia mesoleuca; 5 - Elaenia sp.2; 6 - Phaeomyias murina; 7 - Stigmatura budytoides; 8 - Rhytipterna simplex; 9 - Muscipipra 
vetula; 10 - Myiarchus tuberculifer; 11 - Rhytipterna simplex; 12 - Lathrotriccus euleri; 13 Attila rufus; 14 - Rhytipterna simplex; 15 - Rhytipterna simplex ; 16 - Megarynchus pitangua; 17 - Myiozetetes similis; 18 - Rhytipterna simplex; 19 - Rhytipterna simplex.

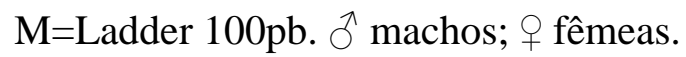

\section{REFERÊNCIAS}

ALEIXO, A. e F. C. Straub. 2007. Coleções de aves brasileiras: breve histórico diagnóstico atual e perspectivas para o futuro. Revista Brasileira de Ornitologia, 15(2):315-324.

COMITÊ BRASILEIRO DE REGISTROS ORNITOLÓGICOS. 2014. Lista Primária das aves do Brasil. Disponível em <http://www.cbro.org.br/CBRO/listabr.htm>.

CORDEIRO, P.H.C. 2000. Estudo da avifauna em fragmentos da Mata Atlântica do Sul da Bahia (levantamento de espécies). Relatório Técnico. [s.l: s.n.].

2003. A fragmentação da Mata Atlântica no sul da Bahia e suas implicações na conservação dos psitacídeos. Em: Prado, P.I., E. C. Landau, R. T. Moura, L. P. S. Pinto, G. A. B. Fonseca e K. N. Alger (Orgs.). Corredor de Biodiversidade da Mata Atlântica do Sul da Bahia. Ilhéus: IESB/CI/CABS/UFMG/UNICAMP, Disponível em: $<\mathrm{http}$ ://ibama.angelfire.com/papagaios.pdf >.

GONÇALVES, B. P. 2013. Sexagem molecular em aves: contribuições à conservação biológica e à divulgação científica. Estado de São Paulo, Brasil. Dissertação de Mestrado. São Paulo: Universidade Estadual Paulista. Instituto de Biociências. Departamento de Genética.

GONZAGA, L. P. 1986. Composição da avifauna em uma parcela de mata perturbada na baixada, em Majé, Estado do Rio de Janeiro, Brasil. Dissertação de Mestrado. Rio de Janeiro: Universidade Federal do Rio de Janeiro. Biblioteca do Museu Nacional.

GRIFFITHS, R.; DAAN, S.; DUKSTRA, C. 1996. Sex identification in birds using two genes. Proc $R$ Soc Lond Ser B, v.263, p.1251-1256.

GRIFFITHS, R.; DOUBLE, M. C.; ORR, K.; DAWSON, R. J. G. 1998. A DNA test to sex most birds. Mol Ecol.; 7: 1071-1075.

LAPS, R. R., P. H. C. Cordeiro, D. Kijawa, R. Ribon, A. A. F. Rodrigues e A. Uejima. 2003. Aves. Em: Rambaldi, D. M. e D. A. S. Oliveira (orgs.). Fragmentação de Ecossistemas. Ministério do Meio Ambiente, Brasília, DF.

MIYAKI, C. Y.; GRIFFITHS, R.; ORR, K.; NAHUM, L. A.; PEREIRA, S. L. ; WAJNTAL, A. 1998. Sex identification of parrots, toucans and curassows by PCR: perspectives for wild and captive populations studies. Zoo Biology, 17: 415-423.

MIYAKI C. Y. 2010. Metodologias de análises genéticas aplicadas ao estudo e à conservação de aves. Em: Von Matter S., F. C. Straube, J. F. Candido Jr, V. Piacentini e I. Accordi (orgs). Ornitologia e Conservação: Ciência aplicada, Técnicas de Pesquisa e Levantamento. - ed. 1 Vol. 1: 415-425.

SILVEIRA, L.F., P. F. Develey, J. F. Pacheco and B. M. Whitney. 2005. Avifauna of the Serra das Lontras-Javi montane complex, Bahia, Brazil. Cotinga, 24: 45-54.

SCHMIDT, G.; THANNHAUSER, S.J. 1945. A method for the determination of determination of desoxyribonucleic acid, ribonucleic acid, and phosphoproteins in animals tissues. The Journal of Biological Chemistry, v. 161, p $83-89$.

VUILLEUMIER, F. 1998. The need to colected birds in Neotopics. Ornitologia Neotropical, 9:201-203. 